\title{
Educação Matemática e Formação Inicial: uso de novas tecnologias em sala de aula
}

\section{Mathematical Education and Initial Training: use of new technologies in the classroom}

\author{
Benedito Rodrigues Brazil ${ }^{1}$ \\ Marco Antônio Escher ${ }^{2}$
}

\begin{abstract}
Resumo: Este artigo é produto decorrente do projeto de ensino de graduação intitulado "O uso do Software SuperLogo no Desenvolvimento de Conceitos Geométricos" vinculado ao Programa de Consolidação das Licenciaturas (Prodocência). O projeto de ensino teve como principais objetivos: aumentar a qualidade das ações voltadas à formação de professores, bem como, explorar as formas de contribuições do programa SuperLogo para o ensino de geometria com prioridade para a formação inicial. O projeto contempla diretamente a formação e o aprendizado profissional dos futuros docentes. Baseado em reflexão sobre diversos autores que abordam a discussão sobre a formação continuada, assim como a utilização das novas tecnologias nesse processo, somado a análise de todo o material do Programa de Ensino aqui relatado, pudemos constatar resultados relevantes que serviram para dinamizar o curso de matemática do Campus do Pantanal (CPAN/UFMS), contribuindo para uma melhor formação acadêmica, científica e técnica dos futuros docentes.
\end{abstract}

Palavras-chave: Educação Matemática. Tecnologias. Superlogo. Geometria.

Abstract: This article is product of the undergraduate teaching project entitled "The Use of SuperLogo Software in the Development of Geometric Concepts" linked to the Bachelor Degree Consolidation Program (Prodocence). The teaching project had as its main objectives: to increase the quality of the actions aimed at teacher education, as well as to explore the ways of contributions of the SuperLogo program to the teaching of geometry with priority for the initial education. The project directly contemplates the formation and professional learning of future teachers. Based on a reflection on several authors that address the discussion about continuing education, as well as the use of new technologies in this process, added to the analysis of all the material of the Teaching Program reported here, we could see some relevant results that served to streamline the Pantanal

\footnotetext{
${ }^{1}$ Mestre em Educação Matemática - UNESP/Rio Claro/SP - Universidade Federal de Mato Grosso do Sul/ Corumbá/MS/Brasil - brbrazil@ibest.com.br

${ }^{2}$ Doutor em Educação Matemática - UNESP/Rio Claro/SP - Universidade Federal de Juiz de Fora - Juiz de Fora/MG/Brasil - escher@ice.ufjf.br

Tangram - Revista de Educação Matemática, Dourados - MS - v.3 n.1, pp. 02-17 (2020)
} 


\section{Educação Matemática e Formação Inicial: uso de novas tecnologias em sala de aula}

Campus (CPAN/UFMS) math course, which contributing to a better academic, scientific and technical formation of future teachers.

Keywords: Mathematical Education. Technologies. SuperLogo. Geometry.

\section{Introdução}

Sem dúvida a utilização das novas tecnologias, sobretudo as computacionais e relacionadas com o uso da internet, se faz presente na sociedade. "A tecnologia fez da sociedade uma sociedade tecnológica" (Castells, 1999). Na escola isso não se mostra diferente, sua entrada pode ser vista em livros e pesquisas, e na prática em sala de aula aqui relatada. A esse respeito Escher (2019) faz consideração importante: "Ainda que na aprendizagem ou no ensino de matemática nas instituições a utilização das TIC esteja ocorrendo em ritmo lento comparado a outros setores do mercado comum (consumo), notamos que mesmo assim está ocorrendo" (Escher, 2019, p. 47). Observe-se, enfim, que corroboramos com outros autores a inegável "revolução tecnológica informacional" (Castells, 1999).

Outra grande contribuição nesse sentido foi dada por Papert (1994), quando se refere aos efeitos da entrada da tecnologia na escola, afirma que

a mudança de um instrumento radicalmente subversivo na sala de aula para
um obtuso instrumento no laboratório de computação não adveio de uma
falta de conhecimento nem de uma falta de software. Eu o explico por uma
inteligência inata da Escola, que agiu como qualquer organismo vivo
defendendo-se de um corpo estranho. Ela ativou uma reação imunológica
cujo resultado final seria digerir e assimilar o intruso (Papert, 1994, p. 42).

É o que vemos nas escolas em que os computadores ficam limitados aos laboratórios, e estes ficam trancados. Chega-se a ouvir depoimentos de professores sobre o fato de a direção da escola desautorizar seu uso para evitar a danificação dos mesmos, ou mesmo colocando nos professores a responsabilidade em caso de avaria dos equipamentos.

Na Educação Matemática, enquanto área de pesquisa, o uso das TIC é visto como Tendência de Pesquisa, no entanto, é preciso levar em conta as ponderações de Escher (2019):

a pesquisa realizada durante o processo de doutoramento evidenciou que ela deve ser tratada de forma mais ampla. Diferentemente de outras tendências de pesquisa na área de Educação Matemática, os estudos sobre as TIC sobrepõem todos os outros campos de conhecimento, os bancos, as

Tangram - Revista de Educação Matemática, Dourados - MS - v.3 n.1, pp. 02-17 (2020) 


\section{Educação Matemática e Formação Inicial: uso de novas tecnologias em sala de aula}

fábricas e todas as atividades humanas. Não que ela não possa ser tratada como uma tendência de pesquisa, mas tratá-la apenas nesse contexto provoca uma redução ao caráter epistemológico, ignorando a característica epidêmica (Escher, 2019, p. 24).

Essa metáfora, tecnologia = epidemia, foi utilizada para descrever o poder que a essas máquinas tecnológicas possuem de atravessar barreiras. Um bom exemplo disso é mesmo que em algumas escolas os computadores estejam confinados em laboratórios trancados, o celular se transformou no computador de bolso, rompendo as proibições aqui elencadas.

Em que pesem considerações ou ponderações, o próprio autor reforça a necessidade: "Por isso, reforço o convite aos educadores de matemática: computadores, calculadoras, aplicativos de celulares...usem!” (Escher, 2018, 73).

Ao corroborar com o quadro anterior, neste artigo faremos o relato da intervenção feita através do projeto de ensino de graduação "O uso do Software SuperLogo ${ }^{3}$ no Desenvolvimento de Conceitos Geométricos". Para realizarmos essa intervenção, nos baseamos integralmente em Motta e Miranda (2008), cuja contribuição do proporciona disponibilizar, para quem inicia estudos no SuperLogo, ou se propõe a ensinar sua linguagem, um texto organizado didaticamente e de forma diferenciada, capaz de se constituir em um instrumento descomplicado e facilitador do manuseio do referido programa.

Procuraremos também expor, buscando exemplificar com o desenvolvimento do projeto aqui exposto, apontamentos entre a importância do uso das Novas Tecnologias de Informação e Comunicação e sua utilização na formação inicial do futuro professor da escola básica.

\section{O projeto}

O desenvolvimento do projeto visou atender demanda crescente sobre o uso de recursos tecnológicos no ensino de matemática. Observamos que os acadêmicos do curso de matemática ingressam na graduação com bastante dificuldade em desenvolver suas competências e habilidades geométricas.

\footnotetext{
${ }^{3}$ SuperLogo é um software baseado no Logo desenvolvido para as versões mais atualizadas do Windows. Tangram - Revista de Educação Matemática, Dourados - MS - v.3 n.1, pp. 02-17 (2020)
} 


\section{Educação Matemática e Formação Inicial: uso de novas tecnologias em sala de aula}

Mesmo nos cursos de formação de professores (em nosso caso os cursos de Licenciatura em Matemática) observamos poucas situações em que os alunos são colocados efetivamente a utilizar as tecnologias computacionais como arte de seus estudos dentro de sala de aula. Quando muito, são incentivados a atividades fora do âmbito da sala, em pesquisas ou estudos do conteúdo, e geralmente impedidos de utilizá-lo em avaliações.

A partir dessa premissa, propusemo-nos desenvolver estas habilidades matemáticas com o uso de um software educacional, o SuperLogo que, segundo relatos de muitos pesquisadores (Valente (1999), Miskulin (1994)), pode desenvolver tais habilidades, não apenas sobre conteúdos geométricos, mas promover a criação de um ambiente propício durante sua aplicação no qual o acadêmico possa se sentir instigado em aplicá-lo em sala de aula e de forma indireta contribuir com as disciplinas de Geometria Plana e Espacial.

Vale ressaltar que o projeto, com carga horária de $60 \mathrm{~h}$, foi uma proposta do Curso de Matemática do Campus do Pantanal (CPAN) ligado ao projeto do PRODOCÊNCIA-UFMS, cujo público alvo foram alunos do curso de Licenciatura em Matemática, e o procedimento efetivou-se em quatro fases: elaboração de material, planejamento das aulas, realização do curso e elaboração de Relatório Final. Nesse sentido, delineou-se um curso com duração de 30 horas, cujos objetivos foram:

- Desenvolver noções básicas de geometria plana e espacial;

- Aplicar ferramentas tecnológicas incentivando sua contribuição ao ensino de matemática;

- Permitir que o aluno adquirisse habilidade e confiança nas construções com o software;

- Exercitar os processos mentais de visualização, generalização e abstração;

- Dotar o aluno de conhecimento para produção de material a ser utilizado em estágios e ou exercício da futura profissão; e

- Estimular a docência.

Para alcançar os objetivos propostos, foram utilizados procedimentos metodológicos que fossem suficientes para chegar a cada um deles, e ainda promover espaço onde ocorressem a troca de informação e o auxílio do professor como mediador (Vygotsky, 1990). E foi assim, foram dinamizadas algumas técnicas indispensáveis:

- Apresentação das principais ferramentas do software;

- Interação direta com uma proposta didática desenvolvida para aplicação em sala de aula;

Tangram - Revista de Educação Matemática, Dourados - MS - v.3 n.1, pp. 02-17 (2020) 


\section{Educação Matemática e Formação Inicial: uso de novas tecnologias em sala de aula}

- Contato direto com uma linguagem de programação implícita na utilização do software;

- Desenvolvimento de atividades de interação do acadêmico com o software;

- Incentivo à construção de novas propostas para o desenvolvimento de trabalhos com o SuperLogo;

E como procedimentos de avaliação e certificação, foi definido que:

- Avaliação contínua do projeto, por meio da observação dos resultados obtidos na resolução dos exercícios trabalhados durante o curso.

- Critérios de Aprovação, ou seja, para recebimento do certificado, o acadêmico deveria atingir no mínimo $75 \%$ de presença e média superior a 5,0.

A escolha pelo uso de um software e da metodologia descrita reside no fato de que eles reúnem características e estudos na área de Educação Matemática (Miskulin, 1994). Vários teóricos apontam que a aprendizagem na perspectiva construtivista (Valente, 1999), depende de ações que caracterizam o "fazer matemática". Aqui entendemos esse fazer como: experimentar, interpretar, visualizar, induzir, conjeturar, abstrair, generalizar e demonstrar. Assim, buscamos no programa SuperLogo, pelo fato deste ser gratuito e de fácil acesso. Esse "fazer matemática" utiliza metodologia apropriada para facilitar os primeiros passos dos que se propõem a ensinar ou estudar geometria com o auxílio do computador.

Mesmo sabendo de que grande parte dos leitores deste artigo desconhecem o SuperLogo, nos parece imperativo, por sua importância no cenário tecnológico e da Educação Matemática, tecer algumas informações e comentários sobre ele.

\section{A escolha do software: Superlogo}

A palavra "Logo" é originada do grego logos, que significa conhecer. Trata-se de uma linguagem interativa que possibilita trabalhar de modo prático o raciocínio, os conceitos de matemáticos, de geometria e de lógica (Papert, 1985).

A linguagem de programação LOGO foi desenvolvida em meados dos anos 60 do século XX no Massachusetts Instituto de Tecnologia, nos EUA, por Seymour Papert e outros colaboradores, com o objetivo de utilizá-la para fins educacionais, e sua primeira versão foi 


\section{Educação Matemática e Formação Inicial: uso de novas tecnologias em sala de aula}

utilizada em 1967. Durante a década de 1970 ele foi distribuído por diversos centros de pesquisas e escolas, movimento que ajudou a aperfeiçoá-1o ${ }^{4}$.

O SuperLogo é um software originado do Logo desenvolvido para Windows. Por ser um software educativo sem fins lucrativos pode ser encontrado gratuitamente no site: https://odisseu.nied.unicamp.br/wp-content/uploads/other-files/Super\%20Logo.zip.

Embora possa ser considerado um software com mais de 50 anos, ele se mostra vivo e muito importante no processo de ensino e aprendizagem, seja de geometria na matemática ou outros conteúdos e disciplinas.

Para Morais (2000), o SuperLogo é algo mais que uma linguagem de programação. É um instrumento proveniente de transformações tecnológicas e que se apresenta como meio auxiliar na transformação do atual sistema educativo, trazendo importantes melhorias no desenvolvimento cognitivo, afetivo e social.

Embora o Logo e seus sucessores sejam carregados de potencialidades em sua utilização no âmbito educacional, suas telas (design) nunca foram providas de atributos (cores, sons), até por que na época em que foram criados (anos 1960, 1970 e 1980), os próprios computadores não utilizavam mouse ou mesmo telas coloridas e placas de som como hoje possuímos. Esse fato poderia ser considerado como um dos motivos para a atenção do usuário estar voltada para o processo e não para o produto final.

Mas hoje podemos encontrar outros softwares que trazem a união desses dois campos, design e potencialidade. Um deles com essas características é chamado de $\mathrm{Scratch}^{5}$, baseado na mesma filosofia e criado nos mesmos centros de pesquisa. Trata-se de uma linguagem de programação facilitada e com uma interface amigável, o qual incentivamos para que todos o conheçam, embora não tenha sido objeto deste Projeto de Ensino.

\section{Desenvolvimento do Projeto}

Como já foi ressaltado, o Projeto foi desenvolvido no Campus da CPAN/UFMS e o respectivo curso no laboratório de computação do mesmo Campus, com a participação de

\footnotetext{
${ }^{4}$ Dados colhidos no site da fundação Logo https://el.media.mit.edu/logo-foundation/index.html , acessado em setembro de 2019.

${ }^{5}$ Scratch é uma linguagem de programação criada em 2007 pelo Media Lab do MIT. Desde 2013 o Scratch 2 está disponível on-line e como uma aplicação para Windows, OS X, e Linux. O Scratch utiliza em grande parte dos princípios do Logo, associado a recursos mais modernos.

Tangram - Revista de Educação Matemática, Dourados - MS - v.3 n.1, pp. 02-17 (2020)
} 


\section{Educação Matemática e Formação Inicial: uso de novas tecnologias em sala de aula}

16 alunos do curso de Matemática, sendo baseado no artigo "Geometria da Tartaruga: Contribuições do Superlogo ao Ensino de Geometria" (Motta e Miranda. 2008).

Buscamos desde o princípio mostrar a importância deste magnífico software no ensino da geometria principalmente aos alunos de séries iniciais. Procuramos, no decorrer do projeto de ensino, trabalhar a teoria e a prática sem dissociação, buscando assim uma interação maior dos alunos com software para que, com isso, os alunos tivessem uma base forte de desenvolvimento e aprendizagem dos principais comandos do SuperLogo.

Foram desenvolvidas atividades de geometria, especialmente preparadas dentro de uma linha metodológica definida, para que os participantes pudessem ser capazes de interagirem e utilizarem o software de maneira fácil e enriquecedora para o curso dos mesmos.

O material escolhido se compõe de uma apostila com 94 páginas, intitulado a tartaruga: contribuições do SuperLogo ao ensino de Geometria" e de autoria de Marcelo Souza Motta e Dimas Felipe de Miranda, UFMG, disponibilizado no ano de 2008. O texto se divide em 10 capítulos, nos quais se pode perceber três partes estruturais: uma introdutória (para conhecimento do software), uma de construções mais simples e fundamentais e uma terceira para aprimoramento com atividades mais complexas e investigativas. Segundo seus autores

O objetivo deste trabalho é disponibilizar, para quem inicia estudos no SuperLogo, ou se propõe a ensinar sua linguagem, um texto organizado didaticamente e de forma diferenciada, que possa se constituir em um instrumento descomplicado e facilitador do manuseio desse programa (Motta e Miranda, 2008).

Trazemos aqui algumas partes como exemplos de orientações do texto utilizado. Inicialmente, para que o leitor tenha uma aproximação do software. Na Figura 1 observa-se a tela inicial, e como aqui já relatada, sem muitos atrativos e com a inexistência de botões e acessos mais amigáveis.

Tangram - Revista de Educação Matemática, Dourados - MS - v.3 n.1, pp. 02-17 (2020) 
Educação Matemática e Formação Inicial: uso de novas tecnologias em sala de aula

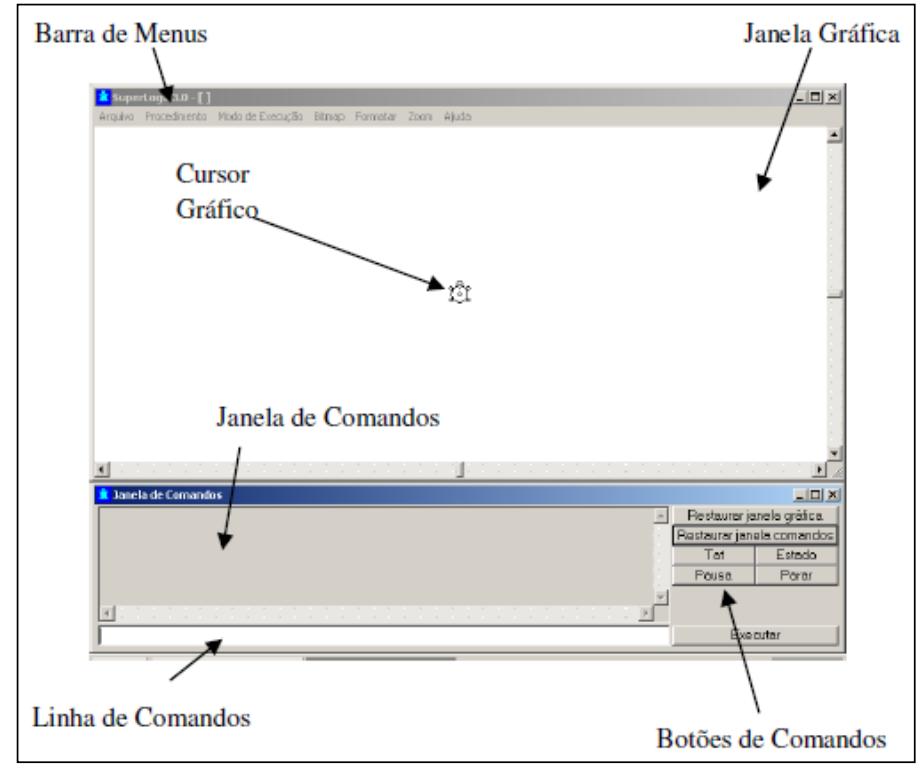

Figura 1: Tela do SuperLogo

Fonte: Motta e Miranda, 2008.

Em seguida (Figura 2 e Figura 3), apresentamos dois exemplos de atividades iniciais, baseada em exemplos previamente colocados pelo autor no material que foi utilizado.

1 - Crie e execute um procedimento para construir um hexágono regular cuja medida do lado seja 50.

Quais conceitos matemáticos ou geométricos devem ser utilizados na execução deste procedimento?

Figura 2: Atividade XII-1

Fonte: Motta e Miranda, 2008.

e

2 - Crie e execute um procedimento para construir um triângulo equilátero cuja medida do lado seja genérica.

Quais conceitos geométricos e matemáticos devem ser utilizados na execução deste procedimento?

Figura 3: Atividade XII-2

Fonte: Motta e Miranda, 2008.

Já aqui vemos a proposta de como abordar a possibilidade de programação no SuperLogo, utilizando o Editor (Aprenda) do software.

Tangram - Revista de Educação Matemática, Dourados - MS - v.3 n.1, pp. 02-17 (2020) 
Educação Matemática e Formação Inicial: uso de novas tecnologias em sala de aula

Estruturação das etapas do procedimento:

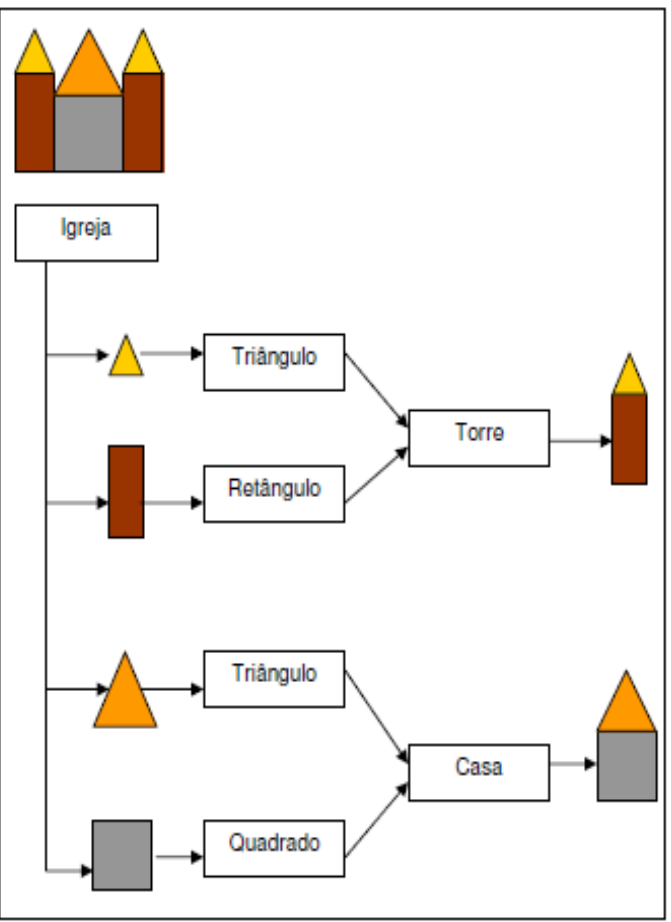

Listagem dos procedimentos do projeto igreja:

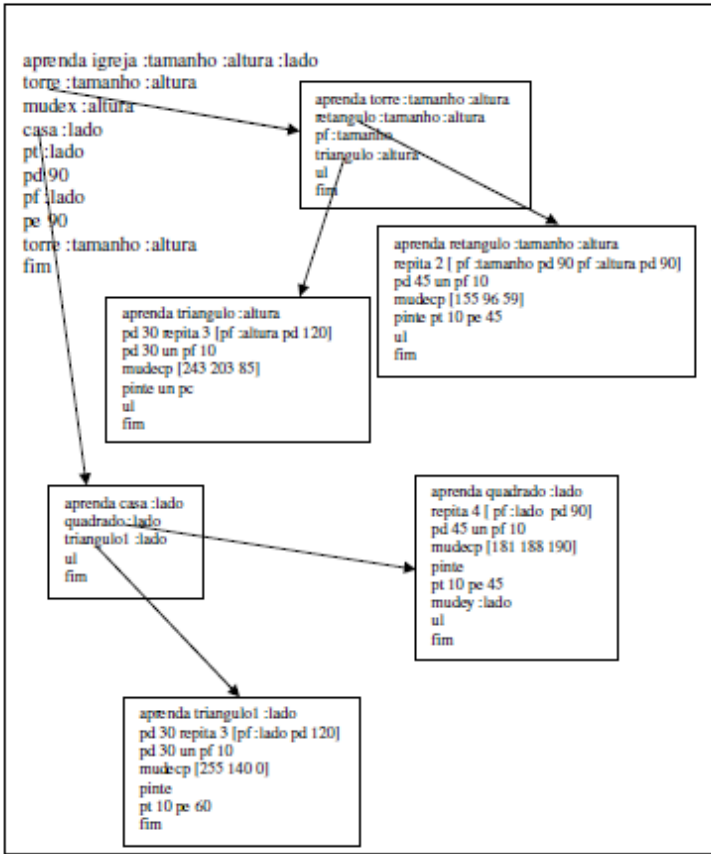

Figura 4 e 5: Atividade de programação

Fonte: Motta e Miranda, 2008.

E finalizando, dois exemplos das atividades investigativas (Ponte ; Brocado ; Oliveira, 2003) colocadas no material utilizado. A primeira (Figura 6), sobre planificações possíveis de um cubo.

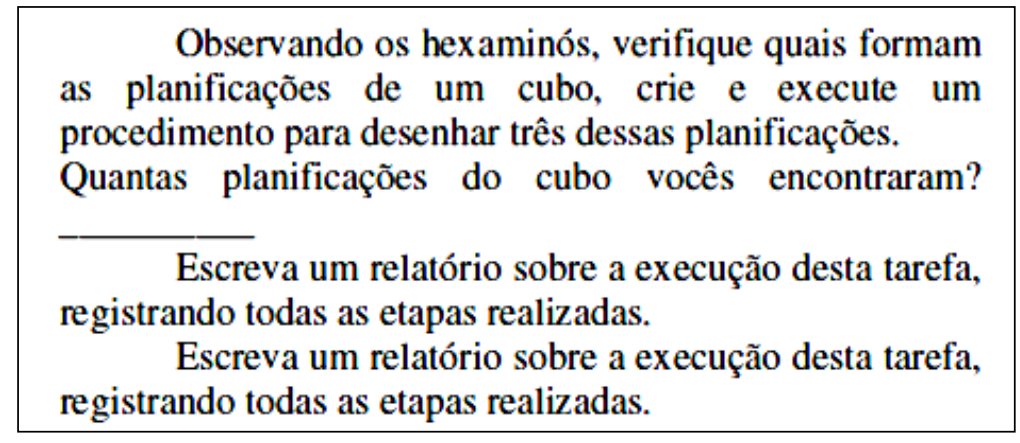

Figura 6: Atividade investigativa 1

Fonte: Motta e Miranda, 2008

E a segunda (Figura 7), propondo uma figura conhecido (semelhante a um rosto)

Tangram - Revista de Educação Matemática, Dourados - MS - v.3 n.1, pp. $02-17$ (2020) 


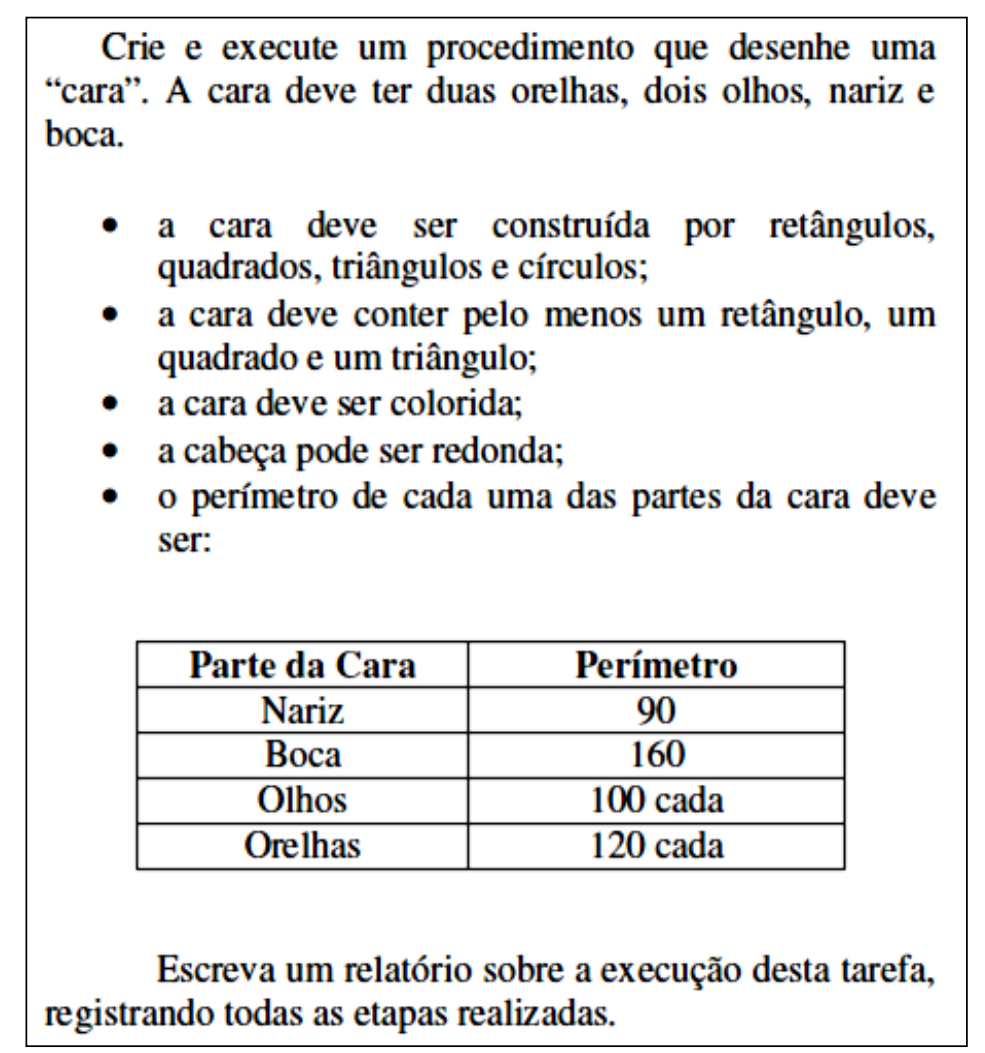

Figura 7: Atividade investigativa 2

Fonte: Motta e Miranda, 2008

Cabe lembrar que o material possui outras diversas atividades, e que quase a totalidade dos alunos participantes do curso conseguiu desenvolvê-las na íntegra.

\section{Alguns relatos}

Ao final do projeto foi solicitado aos alunos que relatassem sobre a importância do trabalho com o SuperLogo; o que o uso do SuperLogo auxiliou em sua aprendizagem de Geometria e Matemática; os conteúdos aprendidos ou ressignificados; a importância do uso do computador na aula; se gostou ou não da realização desta atividade; principais conclusões da atividade. As falas não foram identificadas por não fazerem parte de análise entre seus interlocutores.

Todos foram unânimes ao afirmar a importância do Software SuperLogo em sua formação profissional, como podemos ver em algumas falas a seguir:

O software SuperLogo, desperta o interesse de aprender do aluno por ser um programa de fácil compreensão e manuseio, se tornando importante ferramenta de aprendizagem, pois trabalha o raciocínio lógico do aluno, 


\section{Educação Matemática e Formação Inicial: uso de novas tecnologias em sala de aula}

a formação de novas opiniões e conceitos matemáticos e também desenvolve novos métodos de aprendizagem. (aluno E)

Vimos que podemos usar desse aprendizado para quando dermos aula ou durante um projeto de geometria. (aluno A)

Aqui podemos perceber a preocupação em suas práticas como futuro professor:

O SuperLogo é muito importante para os alunos que fazem o Curso de matemática, pois no futuro poderão usar para ensinar os futuros alunos ensinando fazer os desenhos geométricos. (aluno D)

Neste relato, a constatação da existência de algumas lacunas em sua formação, problema esse que precisa ser refletido e superado.

Trazendo o uso do super logo para a área acadêmica percebemos que a utilização desse recurso possibilita uma revisão de conteúdos elementares da geometria que com o passar do tempo nós erroneamente deixamos de lado. E tão importante quanto a revisão de conteúdos elementares deve-se destacar que para nós acadêmicos de um curso de licenciatura em matemática, tem-se grande importância o aprendizado de um novo recurso que possa vir a ser utilizado no processo de ensino da matemática futuramente. (aluno E)

A importância, potencialidade e presença do uso das tecnologias também foram enunciadas pelos alunos

Estamos sendo instruídos para modificar o ensino da matemática, sair do tradicional, e a tecnologia está aí para nos ajudar, o que temos que fazer é nos especializar e informar sobre tudo que envolve o ensino computacional. (aluno C)

e

Os alunos têm a oportunidade de acertar ou errar e, quando erram, podem investigar o motivo do erro, tendo a oportunidade de "fazer" e "refazer" suas atividades. (aluno B)

e

O software me auxiliou a rever alguns conceitos matemáticos já esquecidos, ajuda na memorização e também a trabalhar com as ferramentas computacionais, material cada vez mais exigido e trabalhado na educação, pois temos que nos aprimorar e caminhar juntos na modernização do ensino, levar para sala de aula ferramenta que o aluno gosta e utiliza no seu cotidiano, pois a cada ano que passa os alunos demonstram maior desinteresse e desgosto pela disciplina de matemática. (aluno E)

Tangram - Revista de Educação Matemática, Dourados - MS - v.3 n.1, pp. $02-17$ (2020) 


\section{Educação Matemática e Formação Inicial: uso de novas tecnologias em sala de aula}

E as surpresas e mudanças de concepções com a participação no Projeto.

Quando começamos o projeto pensei que iríamos utilizar somente o computador como ferramenta, porém com o passar das aulas vi que iríamos precisar saber algumas fórmulas relacionadas à geometria, isso foi importante para mim, pois eu já estava entrando em conteúdos relacionados a geometria, conteúdos que utilizamos durante o projeto todo. (aluno A)

Consideramos que são depoimentos importantes da prática reflexiva em que os alunos participaram, despertando o interesse, a criatividade e a reflexão da importância dela.

\section{A formação inicial do professor}

A maioria das pesquisas na área de Educação Matemática tem revelado o quadro de fracasso que o ensino de Matemática tem atravessado. Fracasso que se percebe mais claramente quando se trata do ensino para camadas populares menos favorecidas socioeconomicamente, ou de locais afastados dos grandes centros, mesmo com a proximidade que as novas maneiras de comunicação possam promover.

Nesse sentido, sabemos dos desafios que nós, professores formadores, temos que enfrentar para criar alternativas para melhorar a formação inicial do futuro professor de Matemática. Notamos que não basta apenas registrar as taxas de evasão e repetência. É preciso criar propostas que visem a superação desse quadro.

Dessa forma, entendemos que a formação inicial do professor passa, antes de tudo, pela localização das causas do fracasso do ensino da matemática e também pela crítica ao modelo de ensino usado pela grande maioria dos professores nas escolas. Vemos a formação do professor crítico/reflexivo em relação ao Ensino Tradicional Vigente (ETV) o eixo fundamental para amenizar nossas preocupações sobre a formação inicial do professor de matemática.

O conceito de professor "professor-reflexivo" foi inicialmente abordado pelo norteamericano Schön ${ }^{6}$ (2000), que se fundamenta na epistemologia da prática ao propor uma

\footnotetext{
${ }^{6}$ Donald Alan Schön (1930-1997) foi professor de Estudos Urbanos no Instituto de Tecnologia de Massachusetts (MIT) nos Estados Unidos embasado pelos autores John Dewey, Luria e Polanyi, entre outros, bastante preocupado com reflexões sobre educação.
}

Tangram - Revista de Educação Matemática, Dourados - MS - v.3 n.1, pp. 02-17 (2020) 


\section{Educação Matemática e Formação Inicial: uso de novas tecnologias em sala de aula}

valorização de uma prática reflexiva na formação dos professores, capaz de responder situações novas e inesperadas (Pimenta, 2010). Entendemos, portanto, que a formação do professor crítico-reflexivo se constitui em uma alternativa às dificuldades decorrentes da formação inicial e continuada.

Como afirma Shön (2000), a reflexão-na-ação ocorre no ato de conhecer na ação. O problema ou necessidade se apresenta e neste momento o professor refletirá em torno do que seria necessário fazer para solucioná-lo. Assim, o professor acaba por dialogar com a situação ocorrente, com vistas a solucionar os problemas eventuais. Refletir sobre a ação, de forma retrospectiva, faz com que o professor analise sua ação desenvolvida (prática), o que desperta nele melhor compreensão e, assim, propor novas ações.

Para Tardif (2007), o professor "prático reflexivo" é aquele que consegue superar a rotinização de suas práticas e ponderar sobre suas ações cotidianas antes, durante e depois de executá-las. Nesta direção, o professor consegue, mesmo imerso na rotinização do mercado em que ele está inserido, se sobressair, ter iniciativas e ser proativo.

\section{Conclusões}

Ao refletir sobre os caminhos da Educação Matemática, sobretudo as formas de análises capazes de promover a "melhora" do ensino, percebemos que o exercício contínuo da docência depende de um firme referencial teórico para sustentá-lo. A busca constante deste procedimento, através do processo de investigação, instaura proposições, alternativas e soluções, que estimulam a articulação entre o ensino e a pesquisa.

Percebemos, a partir do desenvolvimento do projeto de ensino que os alunos passaram a produzir seus próprios conhecimentos. $\mathrm{O}$ ambiente permitiu a expressão ampla da resolução de um problema, segundo uma linguagem de programação. O programa pode ser verificado por meio da sua execução e, com isso, possibilitou ao usuário verificar suas ideias e conceitos. Se existisse algo errado, ele poderia analisar o programa e identificar o erro, que foi tratado como uma fase necessária à sua estruturação cognitiva (Brazil, 1998).

Para concluirmos, destacamos a seguir alguns resultados encontrados que julgamos relevantes:

- Os alunos interagiram diretamente com uma proposta didática desenvolvida para aplicação posterior em sala de aula;

Tangram - Revista de Educação Matemática, Dourados - MS - v.3 n.1, pp. 02-17 (2020) 


\section{Educação Matemática e Formação Inicial: uso de novas tecnologias em sala de aula}

- Os acadêmicos tiveram contato direto com uma linguagem de programação implícita na utilização do software;

- Para cada item da proposta foram desenvolvidas atividades de interação do acadêmico com o software;

- Os participantes sentiram-se motivados à construção de novas propostas para o desenvolvimento de trabalhos com o SuperLogo;

- Puderam rever e aprimorar conceitos de matemática considerados esquecidos pelos participantes.

Mesmo depois de mais de 50 anos de existência desse software (ainda que numa versão menos desenvolvida), e do nosso primeiro contato com o software Logo tenha sido efetivado em 1989, ele se torna presente e ativo como importante ferramenta, dentre as inúmeras ligadas às novas tecnologias, justificando cada vez mais a necessidade de integrarmos as aulas com os recursos tecnológicos computacionais.

As observações das atitudes e produções dos alunos durante o curso, aliadas com as declarações dos participantes nos fazem afirmar que o SuperLogo continua sendo uma importante ferramenta tecnológica para o desenvolvimento de conceitos geométrico na formação inicial do futuro professor de Matemática.

Assim, ao refletir sobre os caminhos da formação do educador, sobretudo as formas de análises capazes de promover a "melhora" do ensino, percebemos que o exercício contínuo da docência depende de um firme referencial teórico para sustentá-lo. A busca constante deste procedimento, através do processo de investigação, instaura proposições, alternativas e soluções capazes de estimular a articulação entre o ensino e a pesquisa. Assim, buscamos traçar alternativas que viabilizem a formação de profissionais atentos, reflexivos e de consciência crítica referente aos modelos ETV.

Com a análise de todo o material do Programa de Ensino aqui relatado, pudemos constatar alguns resultados relevantes que serviram para dinamizar o curso de matemática do Campus do Pantanal (CPAN/UFMS), o que contribuiu para uma melhor formação acadêmica, científica e técnica tanto dos professores envolvidos como dos futuros docentes.

Não obstante, a reflexão sobre a prática nos coloca frente a desafios, porém com indicativos e amparados no referencial de faz-se necessário desenvolver ambientes semelhantes ao programa proposto.

Tangram - Revista de Educação Matemática, Dourados - MS - v.3 n.1, pp. 02-17 (2020) 
Educação Matemática e Formação Inicial: uso de novas tecnologias em sala de aula

\section{Referências}

Brazil, B. R., (1998). A Prática de Ensino de Matemática: Alternativas e Desafios na Formação do Professor, Rio Claro: UNESP/IGCE, Dissertação de Mestrado.

Castells, M. (1999). A Sociedade em Rede - A Era da Informação: economia, sociedade e cultura, volume 1. São Paulo: Paz e Terra.

Escher, M. A. (2018). Tecnologias na sala de aula: e agora? In: CESAR, E. T. (organizador) Ciência em dia: jornadas de divulgação científica: a matemática está em tudo. $1^{\mathrm{a}}$ Edição, São Paulo: Livraria da Física p. 53-74.

Escher, M. A., Miskulin, r. G. S. (2019). Dimensões Teórico-Metodológicas do Cálculo Diferencial e Integral: perspectivas histórica e de ensino e aprendizagem. Revista de Investigação e Divulgação em Educação Matemática, Juiz de Fora, n. 1, v. 3, p. 22-48, jan./jun.

Miskulin, R. G. S. (1994). Concepções teórico-metodológico baseadas em Logo e em resolução de problemas para o processo de ensino/aprendizagem da geometria. 281p. Dissertação (Mestrado em Educação) - Faculdade de Educação, Universidade Estadual de Campinas, Campinas.

Miskulin, R.G.S., Escher, M.A., Silva, C.R.M. (2007). A Prática Docente do Professor de Matemática no Contexto das TIC: uma experiência com a utilização do MAPLE em Cálculo Diferencial. Revista de Educação Matemática, vol. 10 Número 11, Gráfica Compacta.

Morais, J. (2000) Linguagem Logo/Ensino-aprendizagem. Porto, ESE do Porto.

Motta, M. S. e Miranda, D. F. (2008). Geometria da tartaruga: contribuições do SuperLogo ao ensino de Geometria, Belo Horizonte: Do Autor, , 94p

Papert, S. (1985). Logo: Computadores e Educação. São Paulo: Brasiliense.

Papert, S. (1994). A máquina das crianças: repensando a escola na era da informática. Porto Alegre, Artes Médicas.

Pimenta e Ghedin (Orgs) (2005) Professor reflexivo no Brasil: gênese e crítica de um conceito/ $3^{\mathrm{a}}$ ed. - São Paulo: Cortez.

Pimenta S. G. (2010). Professor Reflexivo: Construindo uma Crítica. In: Professor Reflexivo no Brasil: gênese e crítica de um conceito / PIMENTA, S.G., GHEDIN, E. (Orgs.). São Paulo: Cortez.

Pimenta, S. G.; Lima, M. S. L. (2010). Estágio e Docência. 5. ed. São Paulo: Cortez.

Ponte, J. P.; Brocado, J.; Oliveira, H. (2003). Investigações Matemáticas na Sala de Aula. Belo Horizonte: Autêntica Editora.

Tangram - Revista de Educação Matemática, Dourados - MS - v.3 n.1, pp. $02-17$ (2020) 
Educação Matemática e Formação Inicial: uso de novas tecnologias em sala de aula

Schön, D. (1995). Formar Professores como Profissionais Reflexivos. In: NOVOA, A. Os Professores e a sua Formação (Coord.) Publicações Dom Quixote Instituto de Inovação Educacional, Lisboa.

Schön, D. (2000). Educando o profissional reflexivo: um novo design para o ensino e a aprendizagem. Porto Alegre: Artmed.

Tardif, M. (2002) Saberes docentes e formação profissional / Maurice Tardif - Petrópolis, R.J: Vozes.

Valente, J. A. (1999). O Professor no Ambiente Logo: formação e atuação. Campinas: Gráfica da UNICAMP.

Enviado: 26/11/2019

Aceito: $24 / 02 / 2020$

Tangram - Revista de Educação Matemática, Dourados - MS - v.3 n.1, pp. 02-17 (2020) 